\title{
AMBIENT NOISE FOR DETERMINATION OF SITE DYNAMIC PROPERTIES AT HURGHADA AND SAFAGA CITIES, RED SEA, EGYPT
}

\author{
Mostafa TONI ${ }^{1)}$, Abd el-aziz Khairy ABD EL-AAL ${ }^{2)}$ and Gad-Elkareem A. MOHAMED ${ }^{2)}$ \\ ${ }^{1)}$ Geology Department, Faculty of Science, Helwan University, 11790 Ain Helwan, Cairo, Egypt \\ ${ }^{2)}$ National Research Institute of Astronomy and Geophysics (NRIAG), Helwan, Cairo, Egypt
}

*Corresponding author's e-mail: mostafa.toni@hq.helwan.edu.eg

\section{ARTICLE INFO}

Article history:

Received 29 July 2015

Accepted 1 February 2016

Available online 26 February 2016

Keywords:

Shear wave velocity

$\mathrm{H} / \mathrm{V}$ spectral ratio

Surface wave dispersion curves

SPAC

Frequency-wavenumber

Thickness of sediments

\begin{abstract}
Recording ambient noise at the surface is increasingly used for the assessment of site response and has become a fundamental task for seismic risk reduction in urbanized areas. Methods based on the measurement of seismic noise, which typically are fast, non invasive, and low cost, have become a very attractive option in microzonation studies. In the current work, we use the ambient noise recordings collected by single seismic stations and two-dimensional arrays to determine the response of the near-surface soil at the two touristic cities of Hurghada and Safaga which are located at the Red Sea coast in Egypt. Based on the horizontal-to-vertical (H/V) spectral ratio Nakamura's technique, recordings of the single stations are analyzed to estimate the fundamental site frequency $\left(f_{0}\right)$. Using the raw noise signals recorded by two arrays, we present a joint inversion scheme for surface wave dispersion curves. In particular, the Rayleigh wave dispersion curves and the $\mathrm{H} / \mathrm{V}$ curves are combined in a joint inversion procedure. We present inversion procedure based on the computation of high-frequency correlation functions between arrays' stations. The calculation of Rayleigh wave phase velocities is based on the frequency-domain SPatial AutoCorrelation (SPAC) and frequency-wavenumber $(f-k)$ methods. Constitutively, a tomographic inversion of the travel-times estimated for each frequency is performed, allowing the vertically varying 1-D shear wave velocity structure below the array to be retrieved. Following the relationship between resonance frequency $\left(f_{0}\right)$ and thickness of sediments, the thickness of unconsolidated sediments at the investigated sites are determined.
\end{abstract}

\section{INTRODUCTION}

It is widely accepted among the earthquake engineering community that the local geological conditions and shallow shear wave velocity structure of a site have a significant effect on earthquake ground motion. This effect is known as the site effect and may cause amplification of earthquake ground motion in frequency ranges unfavorable for buildings and structures especially in the presence of soft sedimentary covers overlying the bedrock. Shear wave velocity imaging is also of particular interest to obtain important information about the local subsoil structure. Hence, the shear wave velocity may play an important role for site-specific ground motion predictions and is considered as a key parameter related to the assessment of seismic hazard in a given site (Bard, 1999; Zandieh and Pezeshk, 2011).

It has been recognized that the site effects can be estimated by means of numerical simulations and experimental and empirical approaches. Because of the high level of amplification caused by the site effects, which can be almost two orders of magnitudes, it could not be neglected in engineering practice. Many authors stated that the ground motion amplification leads to high level of damages over soft soil and unconsolidated deposits than consolidated sediments and hard rocks (Nakamura, 1989; Duval et al., 1994; Lachet et al., 1996; Bard, 1999; Parolai et al., 2002 and 2004; Abd el-aal et al., 2015). Delineation of unconsolidated sediment thickness and geometry of the underlying bedrock is an important component of many seismological studies, particularly those involving the development of conceptual and numerical models of subsurface lithology and sediments amplification factors.

Recently, the experimental passive seismic techniques have received considerable attention because of the easiness to use passive sources as well as the possibility of investigating deep sedimentary structures at low cost compared to boring techniques (Satoh et al., 2001b). The use of passive techniques is explained by the fact that these applications are based mainly on surface waves, which are by far the strongest seismic waves excited by ambient noise.

Many recent works on experimental passive seismic processing have focused mainly on two procedures: The first one is the seismic interferometry which recently becomes popular in a variety of applications (Curtis et al., 2006; Wapenaar et al., 2008; Schuster, 2009; Snieder et al., 2009). The 
fundamental of this application is that a random wavefield has correlations, which, on average, take the form of the Green's function of the media. The technique hypothesis between pairs of receivers, the Green's function can be extracted from crosscorrelations of ambient noise recorded at both receivers, in turn allowing an estimate of the propagation delay between the stations. Yang et al. (2007) and Bensen et al. (2008) reconstructed traveltime measurements of Rayleigh waves from seismic noise at lower frequencies to produce high-resolution images on continental scales while some other authors used them at regional scales (Shapiro et al., 2005; Kang and Shin, 2006; Yao et al., 2006; Lin et al., 2007; Moschetti et al., 2007). The applicability of the method has also been shown for higher frequencies at local scales (Chavez-Garcia and Luzon, 2005; Brenguier et al., 2007; Picozzi et al., 2009). The second one is the horizontal-to-vertical $(\mathrm{H} / \mathrm{V})$ spectral ratio method which is an experimental technique to evaluate some characteristics of soft soil. This method is known as the Nakamura's technique (Nakamura 1989), and was firstly introduced by Nogoshi and Igarashi (1971) based on the initial studies of Kanai and Tanaka (1961). Due to its simplicity, low-cost, and minimal disturbances to the other activities especially in the inhabitant areas, the $\mathrm{H} / \mathrm{V}$ technique has been frequently adopted in seismic microzonation investigations. The $\mathrm{H} / \mathrm{V}$ technique requires recording of a single station to derive the local site conditions and uses the vertical component as a reference. If there is strong impedance contrast between the sediments and the underlying bedrock, the peak of the $\mathrm{H} / \mathrm{V}$ spectral ratio curve appears at the fundamental resonance frequency of the soil.

Application of the passive seismic techniques is used frequently in Egypt to obtain fundamental site frequency and amplification factors for seismic hazard assessment at several areas (Abd el-aal, 2008, 2010a, 2010b, 2010c, 2013; Abdel-Rahman et al., 2012; El-Hady et al., 2012; Toni, 2007, 2012; Abd el-aal and Soliman, 2013; El-Eraki et al., 2013; Abd el-aal et al., 2015). The rapid increasing in urbanization, tourist beach resorts and land use planning in the Red Sea coastal areas are the motivation of the current study. We applied the background noise techniques to estimate the fundamental site frequency, shear wave velocity structure and thickness of subsurface layers at Hurghada and Safaga cities which are two touristic and growing urban settlements along the Red Sea coast in Egypt.

\section{LOCATION AND GEOLOGIC SETTING OF THE INVESTIGATED AREAS}

Hurghada is the capital of the Red Sea Governorate. It is located on the western coast of the Red Sea, $500 \mathrm{~km}$ south-east of Cairo, and stretches for about $36 \mathrm{~km}$ along the seashore (Fig. 1). It is bordered by Ras Gharib city in the north and Safaga city in the south. Hurghada is a main tourist center on the Red Sea coast in Egypt. The another investigated site is Safaga city which is a marine port and tourist city located at about $53 \mathrm{~km}$ south of Hurghada (Fig. 1). In the last twenty years, Hurghada and Safaga cities have been subjected to rapid and increasing changes in land use patterns, particularly with the growth of tourist activities, construction of many new resorts and the subsequent increase of population.

The topographic features of the Eastern Desert where the study areas lie differ from the other regions in Egypt. The Egyptian Eastern Desert is relatively mountainous (Fig. 2). The elevation rises abruptly from the Nile, and a downward-sloping plateau of sand gives way within $100 \mathrm{~km}$ to arid, defoliated, rocky hills running north and south between the Sudan border and the Nile Delta. The hills reach elevations of more than $1.900 \mathrm{~m}$. The region's most prominent feature is the easterly chain of rugged mountains, the Red Sea Hills, which extend from the Nile Valley eastward to the Gulf of Suez and the Red Sea. This elevated region has a natural drainage pattern that rarely functions because of insufficient rainfall. It also has a complex of irregular, sharply cut wadis that extend westward toward the Nile. The desert environment extends all the way to the Red Sea coast (Said, 1990; Geography of Egypt, https://en.wikipedia.org/wiki/Geography_of_Egypt).

Figure (2) shows the geological map around Hurghada and Safaga cities. The study areas could be divided into three main zones: 1) Coastal plain zone which is represented by a low land that occurs between the Red Sea to the east and a hilly and mountain terrain further west. This zone is mainly covered by Quaternary and Pliocene deposits. Sabkha and recent wadi deposits appear in scatter sites in this zone. These sediments overlay directly the basement complex which appear to the west (Fig. 2). Consequently, the thickness of these sediments is generally increased toward the Red Sea. The Miocene sediments are particularly located to the west of this zone. 2) A high land zone which appears in the west as chain of rugged hills and composed of igneous and metamorphic rocks. This zone represents the eastern part of the Red Sea Mountains. 3) The drainage pattern (Conoco, 1987 and Said, 1990).

The area is structurally controlled by the tectonic framework of the Red Sea, Gulf of Suez and Gulf of Aqaba which form the northern branch of the East African Rift System. The area is subjected to a relatively high level of local seismicity, including several shocks of sizable magnitude (e.g., 31 March 1969 Gulf of Suez earthquake $\left(\mathrm{M}_{\mathrm{b}}=6\right), 22$ November 1995 Gulf of Aqaba earthquake $(\mathrm{Mw}=7.3)$, 30 January 2012 Ras Mohamed earthquake $\left.\left(\mathrm{M}_{\mathrm{b}}=4.6\right)\right)$ due to its closeness to the relative motion at the triple junction among the African plate, Arabian plate and Sinai sub-plate (Toni, 2007 and Abu El-Nader, 2013). Toni (2007) reported that the area around Hurghada is subjected to tectonic movements during the geological history and a number of complex structural elements appear on the surface. The main trend of these elements is NW -SE parallel to the Red Sea and Gulf of Suez direction while the other trend is oriented ENE-WSW perpendicular to the former. 


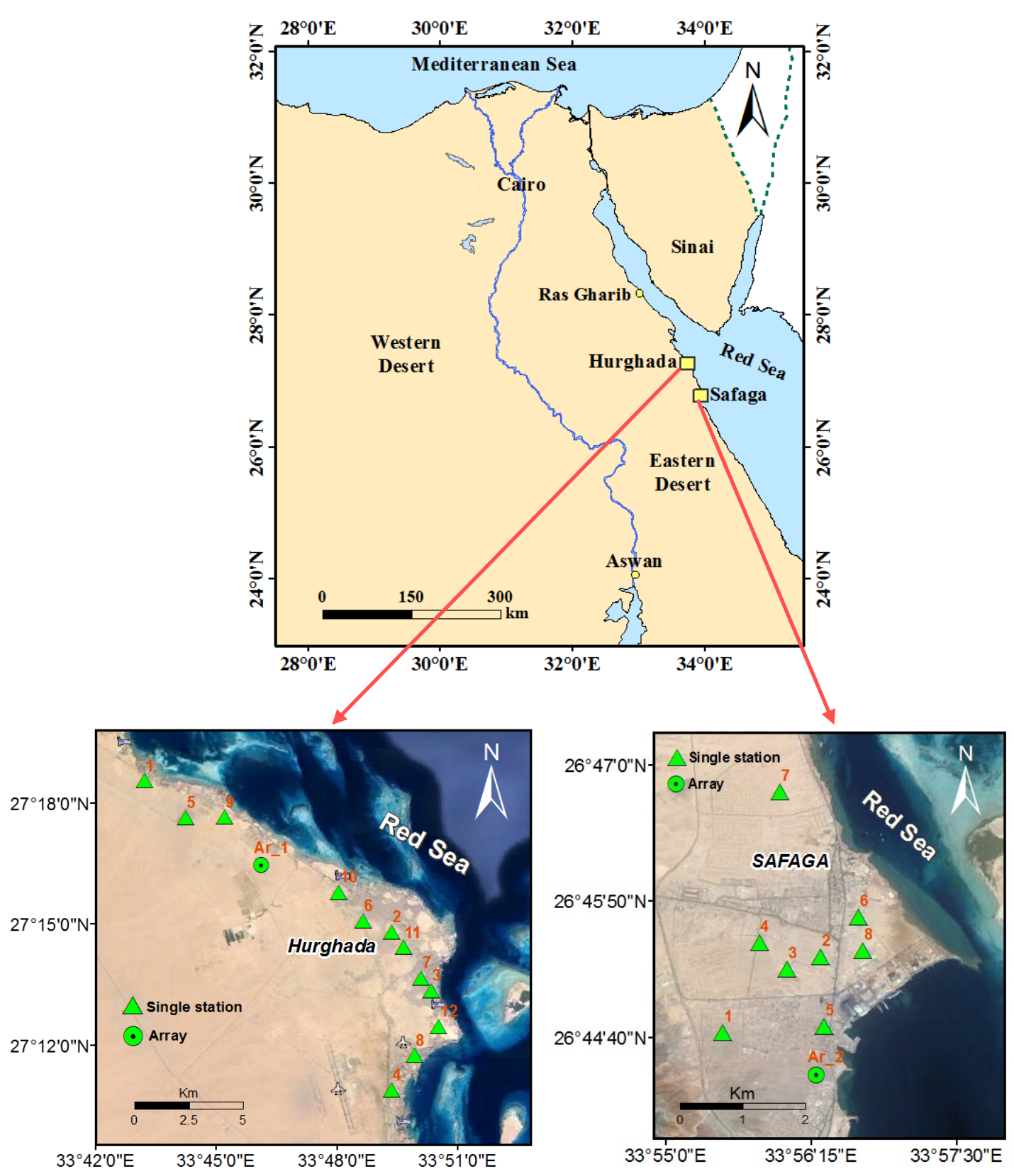

Fig. 1 Map of Egypt showing the locations of Hurghada and Safaga cities (upper map). Lower maps show the distribution of the measured sites at Hurghada (left) and Safaga (right).

\section{METHODS AND SCHEMES}

The proposed scheme depends on observations derived from seismic noise recordings collected by 2$\mathrm{D}$ array of seismic stations, in which we present a joint inversion scheme for surface wave dispersion curves. In particular, the Rayleigh wave dispersions which will be innovatively combined in a joint inversion procedure carried out following a global search approach (i.e., the Genetic Algorithm). We present inversion procedure based on the computation of high-frequency correlation functions between stations of a small-scale array deployed for recording ambient noise in Hurghada and Safaga cities. The calculation of Rayleigh wave phase velocities is based on the frequency-domain SPatial AutoCorrelation (SPAC) technique. Constitutively, a tomographic inversion of the travel-times estimated for each frequency is performed, allowing the vertically varying 1-D shear-wave velocity structure below the array to be retrieved. The proposed scheme depends on the previous work of Aki $(1957,1965)$.

Aki $(1957,1965)$ proposed the analysis of ambient noise as a tool for investigating the shear wave velocity structure below a site, which can be used to calculate the site response by numerical simulations. He derived dispersion curves by analyzing the correlation between noise recordings made at sites close to each other.

Aki $(1957,1965)$ assumed that noise represents the sum of waves propagating in a horizontal plane in different directions with different powers, but with the same phase velocity for a given frequency. He also 


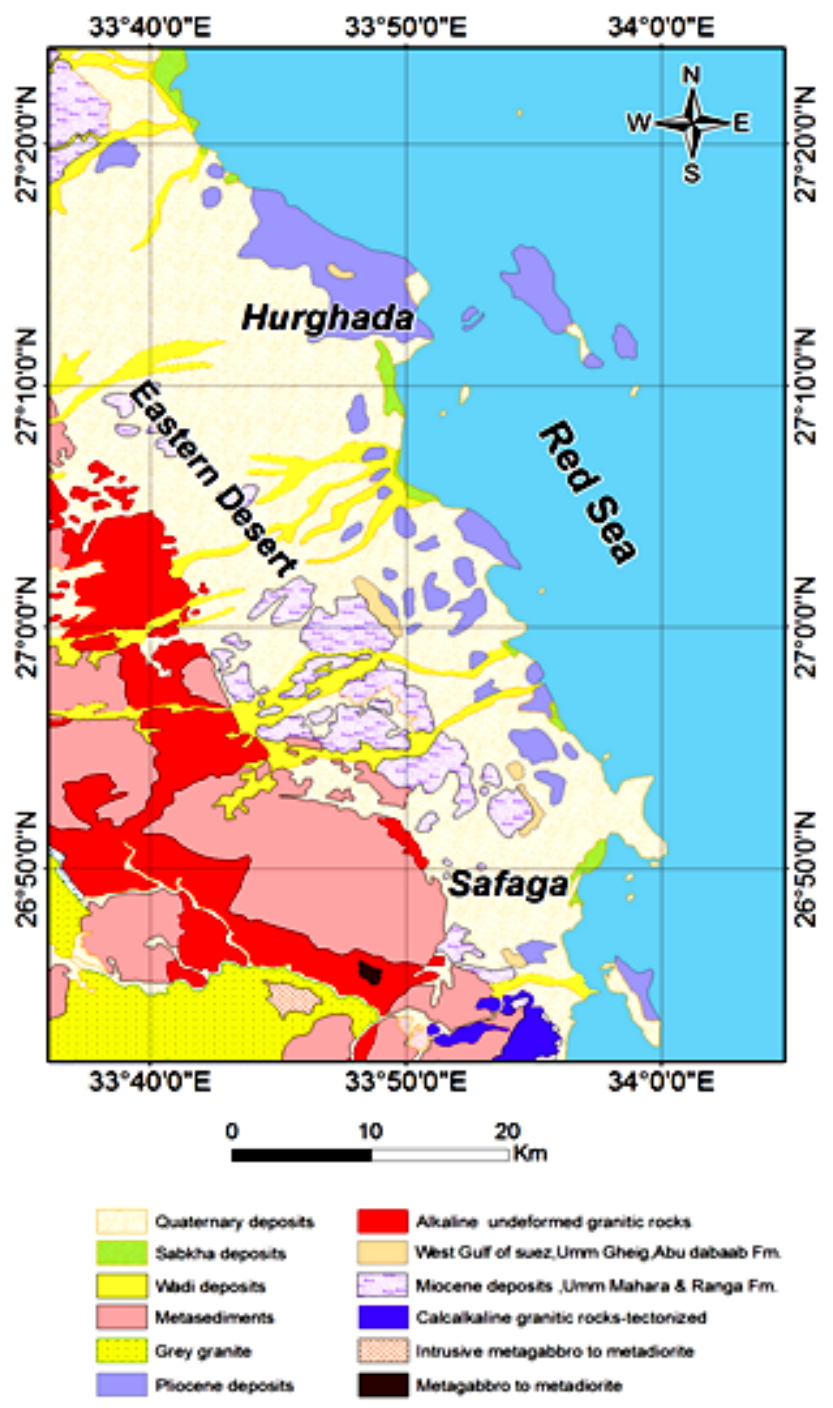

Fig. 2 Geological map around the study areas (Modified after geological map of Egypt, EGPC 1987).

assumed that waves with different propagation directions and different frequencies are statistically independent. A spatial correlation function can therefore be defined as:

$\phi(r, \lambda)=<u(x, y, t)(x+r \cos (\lambda), y+r \sin (\lambda), t)>(1)$

$u(x, y, t)$ is the velocity observed at point $(x, y)$ at time $t ; r$ is the inter-station distance; $\lambda$ is the azimuth and $<$ $>$ denotes the ensemble average.

An azimutal average of this function is given by:

$\phi(r)=\frac{1}{\pi} \int_{0}^{\pi} \phi(r, \lambda) d \lambda$

The autocorrelation function is related to the power spectrum $\phi(\omega)$ by:

$\phi(r)=\frac{1}{\pi} \int_{0}^{\infty} \phi(\omega) J_{0}\left(\frac{\omega r}{c(\omega)}\right) d \omega$ where $J_{0}\left(\frac{\omega r}{c(\omega)}\right)$ is the zeroth order Bessel function and $c(\omega)$ is the frequency dependent phase velocity. The space-correlation function for one angular frequency $\omega_{0}$ normalized to the power spectrum, will be of the form

$\phi\left(r, \omega_{0}\right)=J_{0}\left(\frac{\omega_{0}}{c\left(\omega_{0}\right)} r\right)$

For every couple of stations (fixed the distance $r$ ) the function $\phi(\omega)$ can be calculated in the frequency domain by means of (Malagnini et al., 1993; Ohori et al., 2002; Okada, 2003):

$\phi(\omega)=\frac{\frac{1}{M} \sum_{m-1}^{M} \operatorname{Re}\left(m S_{j n}(\omega)\right)}{\sqrt{\frac{1}{M} \sum_{m-1}^{M} m S_{j j}(\omega) \sum_{m-1}^{M} S_{n n}(\omega)}}$ 
where $m S_{j n}$ is the cross-spectrum for the $m$ th segment of data, between the $j$ th and the $n$th station, and $M$ is the total number of used segments. The power spectra of the $m$ th segment at station $j$ and station $n$ are $m \mathrm{~S}_{j j}$ and $m \mathrm{~S}_{n n}$, respectively. Spatial correlation values $\phi(\omega)$ are plotted as function of distance. A grid search procedure is applied to find the $c(\omega)$ that gives the best fit to the data. The $c(\omega)$ values plotted versus the frequency provide the dispersion curve. Since the phase velocity is related to the shear wave velocity structure of the site, the dispersion curve can be inverted to obtain the model that allows bettering justifying the observed data.

We also used the frequency-wavenumber $(f-k)$ method as another supporting tool to drive the dispersion curve from the raw signals. The $(f-k)$ analysis assumes plane waves to travel across the array of sensors laid out at the surface. Considering a wave with frequency $f$, a direction of propagation and a velocity (or equivalently $k_{x}$ and $k_{y}$, wavenumbers along $X$ and $Y$ horizontal axis, respectively), the relative arrival times are calculated at all sensor locations and the phases are shifted according to the time delays. The array output is calculated by the summation of shifted signals in the frequency domain. If the waves travel with a given direction and velocity, all contributions will stack constructively, resulting in a high array output (usually called the beam power, Capon, 1969). The location of the maximum of beam power in the plane $\left(k_{x}, k_{y}\right)$ provides an estimate of the velocity and of the azimuth of the travelling waves across the array (Wathelet, 2005 and Wathelet et al., 2008).

The second scheme proposed in this work is the $\mathrm{H} / \mathrm{V}$ spectral ratio approach (Nakamura, 1989). In contrast to active shallow seismic techniques (e.g., reflection, refraction or multi-channel surface-wave), which use an artificial seismic source such as hammer blow, weight drop or an explosive charge to obtain a seismic response from the subsurface, the $\mathrm{H} / \mathrm{V}$ method is a passive method that uses three-component measurements of ambient noise. In order to obtain the fundamental frequency $\left(f_{0}\right)$ of the uppermost sedimentary layers in site of interest, a microtremor surveys may be the best choice for this purpose. In the current work, the $\mathrm{H} / \mathrm{V}$ spectral ratio technique is applied to estimate the site response from ambient noise recordings in the investigated sites. Nakamura hypothesized that the vertical component of ambient noise is relatively uninfluenced by the sediments, and can therefore be used to remove the site effects from the horizontal components. By other words, the H/V ratio is the ratio between the Fourier spectra of the horizontal and vertical components of seismic noise.

$$
H / V(\omega)=\left\{\left[S^{2}(\omega)_{N S}+S^{2}(\omega)_{E W}\right] / 2 S^{2}(\omega)_{V}\right\}^{1 / 2}
$$

where the terms $\left[S(\omega)_{N S}\right.$ and $\left.S(\omega)_{E W}\right]$ and $\left[S(\omega)_{V}\right]$ are the ratio of the horizontal and vertical spectra of ambient noise respectively and $\omega$ is the angular frequency.

Nakamura also suggested that the $\mathrm{H} / \mathrm{V}$ ratio is an adequate estimation of the site response to S-waves, providing reliable estimates about resonant frequencies. Several authors such as Duval et al. (1994) and Lachet et al. (1996) confirmed that these ratios are much more stable than the raw noise spectra. The main target of this study is to exhibit the subsurface dynamic characteristics of soil layers. The resonance frequency is determined through analysis of the spectral ratio of the horizontal and vertical components of ambient noise. The $\mathrm{H} / \mathrm{V}$ method has been used for microzonation studies to predict site response to earthquake seismicity (e.g. Nakamura, 1989; Konno and Ohmachi, 1998; Rial et al., 1992) and as a method to estimate unconsolidated sediment thickness, map the bedrock surface, and infer fault locations (e.g., Ibs-von Seht and Wohlenberg, 1999; Delgado et al., 2000; Parolai et al., 2002). The resonance frequency, $f_{r n}$, of the $n$ mode is related to sediment thickness $Z$ can be determined from the relation:

$f_{r n}=(2 n+1)\left(V_{s} / 4 z\right)$

where $V_{s}$ is the average shear-wave velocity in $(\mathrm{m} / \mathrm{s})$ of the sediment layer overlying bedrock, $Z$ is given in meters, and $f_{r n}$ is given in $(\mathrm{Hz})$ (Ibs-von Seht and Wohlenberg, 1999). The fundamental resonance frequency, $f_{r 0}$, is given when $n=0$ and higher-order modes of the resonance frequency are given by $n \geq 1$. The relation between sediment thickness, $Z$, and resonance frequency can be given by:

$$
Z=a f_{r_{0}}^{b}
$$

where $a$ and $b$ are determined empirically from nonlinear regression of $f_{r 0}$ data acquired at sites where $Z$ is known (e.g., adjacent to boreholes). One advantage of equation (8) is that explicit measurement of $V_{s}$ is not required. Ibs-von Seht and Wohlenberg (1999) and Parolai et al. (2002) published equations relating sediment thickness to resonance frequency based on correlation to borings in Germany. They found that the values of fitting parameters $a$ and $b$ equal to 96 and -1.388 respectively while Parolai et al. (2002) estimated the values of $a$ and $b$ equal to 108 and -1.551 respectively.

\section{DATA ACQUISITION AND MEASUREMENTS}

The following is a brief description of the data acquisition used in both schemes:

\subsection{SEISMIC NOISE ARRAY}

An array of nine portable seismic stations was installed at Hurghada and Safaga cities (Figs. 1 and 3 ). The data set has been used here for a study of site effects, based on the inversion of Rayleigh wave dispersion curves. All stations were equipped with Taurus seismographs and high sensitivity three channel Trillium 120s seismometers, having a natural 
frequency of $0.008 \mathrm{~Hz}$. The Taurus seismograph, which was manufactured by Nanometrics Co., was used as a digital seismograph. Taurus is a modern field portable and highly flexible digital seismograph, has 24 - bits resolution and a dynamic range of $132 \mathrm{~dB}$, which is achieved using high performance sigma-delta analog to digital converters. Figure 3shows the selected array geometry, which is characterized by side lengths of $100 \times 100 \mathrm{~m}$, and a minimum inter-station distance of $10 \mathrm{~m}$. The selected range of station inter-distances allows for an optimal compromise between resolution at shallow depths and the maximum depth of investigation. Seismic noise was recorded at a sampling rate of 100 samples per second for over 2 hours record duration.

\subsection{SINGLE STATION RECORDINGS}

The background noise measurements were carried out at 12 sites in Hurghada city and 8 sites in Safaga city as shown in Figure 1. The data was recorded by using the same instruments of Trillium 120s seismometers and Taurus digital seismograph. To ensure reliable experimental conditions, the guidelines proposed in the SESAME project (2004) were strictly followed. Microtremor survey has been performed at total 20 sites with a continuous recording system at a sampling rate of 100 samples per second for at least $60 \mathrm{~min}$ record duration.

\section{DATA PROCESSING AND ANALYSIS}

In the first scheme of data processing, the Rayleigh wave phase velocities were computed by analyzing the seismic noise recorded at the vertical component, using 200 windows of signal of 30 seconds length. In order to reduce leakage problems, each signal window was tapered for $5 \%$ of its length using a cosine function. The space correlation values for every frequency are plotted as a function of distance, and an iterative grid search procedure was performed in order to find the Rayleigh phase velocity value that gives the best fit to the observed data. The best fit is achieved by minimizing the root mean square (RMS) of the differences between the values calculated.

Figure 3 shows that the Raleigh wave dispersion curves improve the resolution of the first two layers of the model. The reason for the improvements in the results from the Raleigh inversion can be understood by analyzing the Jacobian matrixes in Figure 3. the Jacobian matrix is defined as the matrix of the first-order partial derivative, here numerically calculated, from the observations of Rayleigh wave dispersion, with respect to the model parameters (in this case, the S-wave velocity at different depth). The distribution of maxima within the Jacobian matrix (Fig. 3) indicates for which change in velocity at depth is each frequency of the Rayleigh wave dispersion more sensitive. At the final step the shear wave velocity model is produced through an inversion process.
The $f-k$ analysis was also applied in the computation of Rayleigh wave phase velocities from the vertical component. The analysis was performed using GEOPSY software (http://www.geopsy.org). During the first phase in data analysis, special attention was paid to determine the reliable frequency range of the dispersion curve, which depends on the array geometry. Theoretical array response that takes into account the real array geometry was computed for the two arrays (i.e. Hurghada and Safaga). The wavenumber limits deduced from the theoretical array response are good estimates of the valid dispersion curve range, as it has been also suggested by Wathelet et al. (2008). The next stage is to derive the dispersion curve from noise array signals. During this stage the following steps were applied on the raw signals: 1) the recorded waveforms are divided into short time windows, the length of which depends on the considered frequency band. Pre-processing methods may be used to reject transients or saturated signals (Bard, 1998 and Wathelet, 2005); 2) Fourier transform is calculated for the signal of each sensor after a proper cutting of time windows; 3) each signal window was tapered for $5 \%$ of its length using a cosine function; 4) the frequency-wavenumber transformation itself is calculated in the frequency domain on the cut signals. Figure 4 shows the Raleigh wave dispersion curves obtained from the $f-k$ analysis for the seismic arrays of Hurghada and Safaga sites. At the final stage, the resulted dispersion curves are inverted using the neighborhood algorithm (Sambridge, 1999 and Wathelet, 2008) to obtain the 1D shear-wave velocity model at the measured sites.

In the second scheme of data processing, 30 windows of 70 seconds duration were selected from the quietest part of the recorded microtremors depending on the ratio of short term averaging (STA) and long term averaging (LTA). This time window has proven to be sufficiently long to provide results at the desired frequency. The recorded data have been processed in relevance to the following procedures: baseline and instrumental correction, band-pass filtering to define the optimum frequency range (from 0.2 to $10 \mathrm{~Hz}$ ), the length of time windows was automatically selected using an anti-STA/LTA trigger algorithm, cosines type window tapering on $5 \%$ of the signal was applied, Fourier spectra of the three components (north-south, east-west, and vertical) were calculated. The calculated Fourier spectra of the three components were smoothed with KonnoOhmachi algorithm, the horizontal components were merged by geometric mean (sqrt (spec EW $\times$ spec $\mathrm{NS}$ )), and the H/V spectral ratios were calculated by dividing the spectra of the merged horizontal $(\mathrm{H})$ components to the spectra of the vertical component (V). A MATLAB code was written to perform the selection of the quietest windows, an amplitude spectrum for each component, $\mathrm{H} / \mathrm{V}$ calculation, and plotting final results in figures and the results were validated by recalculation using the international 


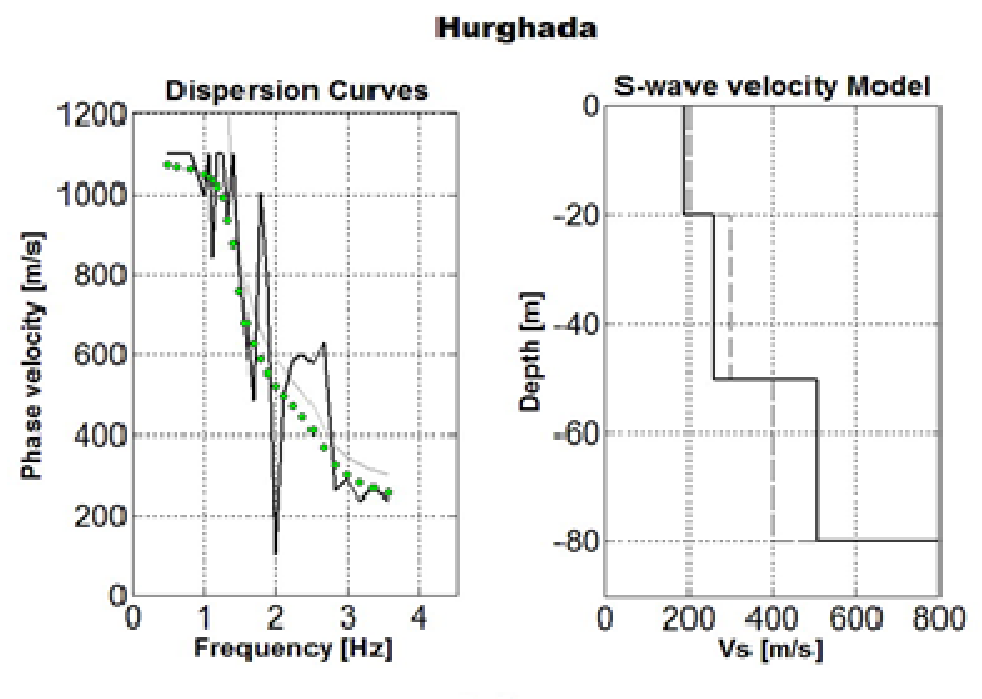

Safaga
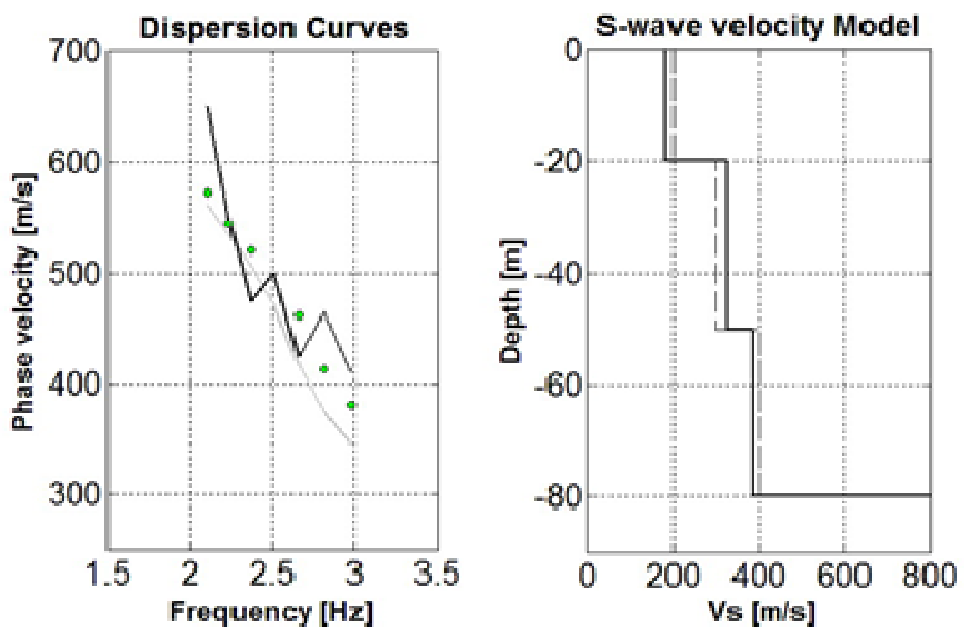

Fig. 7 The right panels illustrate S-wave velocity profiles resulted from the Rayleigh wave joint inversion (GA analysis) at Hurghada and Safaga cities. Left panels show the observed (black), theoretical (grey) Rayleigh wave dispersion curve and misfit (green points).

software Geopsy (http://www.geopsy.org). Figures 5 and 6 illustrate examples of the $\mathrm{H} / \mathrm{V}$ curves obtained from the investigated sites in Hurghada and Safaga respectively. We estimated the site fundamental frequency $\left(\mathrm{f}_{0}\right)$ by taking the frequency corresponding to the peak of the lowest frequency at $\mathrm{H} / \mathrm{V}$ curve. Even if, as often occurs in urban areas, that $\mathrm{H} / \mathrm{V}$ curves exhibit local narrow peaks or troughs, such peaks or troughs have usually industrial origin, related to some kind of machinery (cars, turbine, generators, etc). As the source is more or less permanent, the original Fourier spectra should exhibit sharp narrow peaks at the same frequency for all the three components. Reprocessing data with less and less smoothing, in the case of industrial origin, the $\mathrm{H} / \mathrm{V}$ peak should become sharper and sharper; on the other hand, this is not the case for a site peak linked with soil characteristics. Another very effective check, which is called the random decrement test and rotation test are to be applied to the ambient vibration recordings in order to derive the "impulse response" around the frequency of interest: if the corresponding damping for the vertical ground motion component $(\mathrm{z})$ is very low (below $1 \%$ ), an anthropic origin may be assumed for that frequency and it should not be considered in the interpretation.

\section{RESULTS AND INTERPRETATIONS}

Figure 7 shows the S-wave velocity profiles deduced from the Genetic Algorithm (GA) inversion procedure of Rayleigh wave dispersion curves at Hurghada and Safaga. The best-fit S-wave velocity profile is characterized by significant impedance contrasts at $20 \mathrm{~m}, 50 \mathrm{~m}$, and $80 \mathrm{~m}$ depths. Using the best-fit $\mathrm{S}$-wave velocity profile, and computing the average Vs velocity at the different impedance contrasts, we estimated the theoretical fundamental frequency $\left(f_{0}\right)$ for SH-waves [i.e., $f_{0}=V_{s} / 4 Z$ ] for the different layers. Interestingly, we found that the value of $f_{0}$ comparable to the peak in the $\mathrm{H} / \mathrm{V}$ curve is found for the impedance contrast at about $90 \mathrm{~m}$ depth, a value of $f_{0}$ around $1.0 \mathrm{~Hz}$ is found. In the light of 

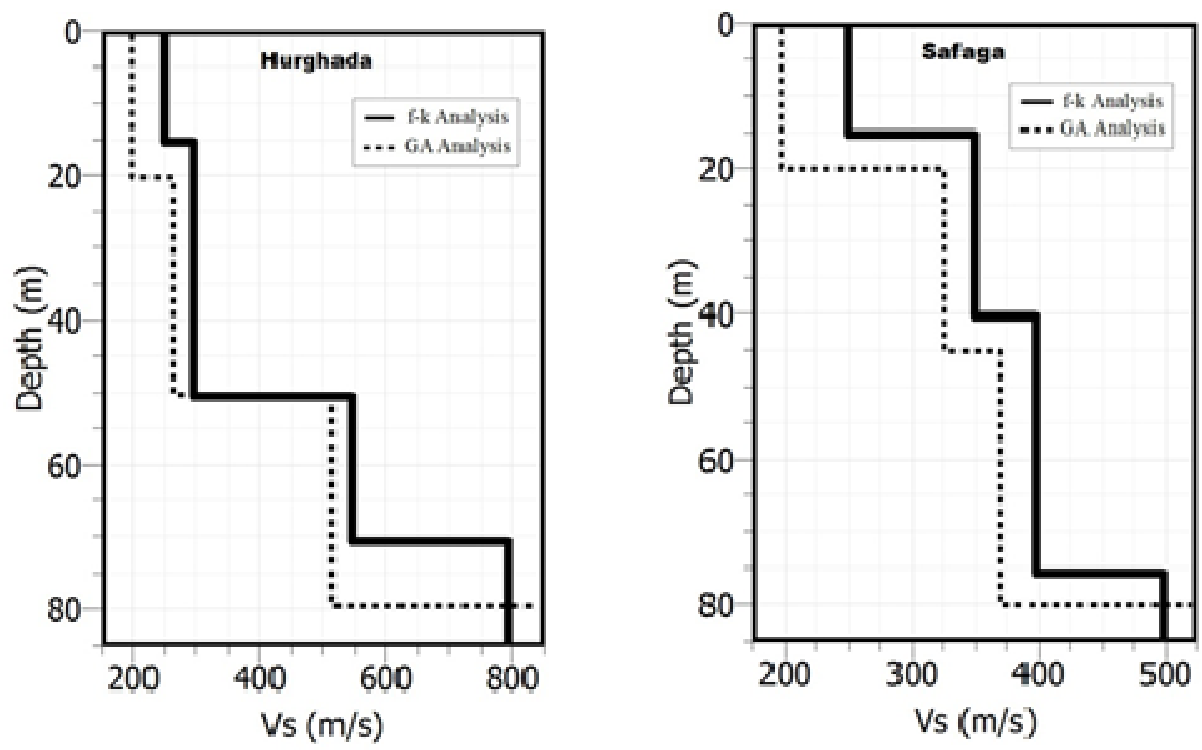

Fig. 9 Final S-wave velocity profiles deduced from GA and f-k analysis at Hurghada and Safaga cities.

these observations, the $\mathrm{H} / \mathrm{V}$ and Rayleigh wave dispersion curves cooperate in constraining the impedance contrast at $80 \mathrm{~m}$.

In order to support the reliability of the obtained results, the dispersion curves obtained from $f-k$ analysis have been inverted to infer the $\mathrm{S}$-wave velocity profiles (Fig. 8). The obtained Vs profiles show multimodels with different misfit values. In this study, we considered the model of lowest misfit. The selection of this model was made visually and automatically in Geopsy software. Comparing the inverted dispersion curves to the measured ones, it has been found that there is a good fitting between the two curves for the two arrays (Fig. 8).

Figure 9 illustrates the final S-wave velocity profiles deduced from both GA and $f-k$ analysis. The comparison between the results of the two applied techniques shows that; there is a relatively good fitting between Vs profiles in terms of Vs values and depth to interfaces. However, the Vs models of $f-k$ analysis show relatively higher velocities than those of GA analysis for the two arrays, but still in the accepted range. The results demonstrate that the two applied techniques were able to investigate approximately the same depth ( 80-90 m)

The H/V analysis of single station ambient noise data resulted in clear and easily identified fundamental frequency peaks that show a good correlation between decreasing the resonance frequency with increasing the depth to bedrock. The obtained results for fundamental frequency $\left(f_{0}\right)$ with standard deviation, corresponding $\mathrm{H} / \mathrm{V}$ amplitude and depth to bedrock at Hurghada and Safaga cities are listed in Table 1. The results exhibit low fundamental frequencies $\left(f_{0} \leq 1.0 \mathrm{~Hz}\right)$ for both cities. This is may be interpreted as: 1) all the measured sites in Hurghada and Safaga cities were carried out in the coastal plain zone which is mainly covered by a thick cover of Quaternary and Pliocene unconsolidated deposits; 2) These results are compatible with the surface geology (Fig. 2) and our field observation regarding thickness of loss sediment in the investigated sites.

Many previous studies (e.g., Mukhopadhyay and Bormann, 2004; SESAME project, 2004; Panou et al., 2005; Hagshenas et al., 2008; Zandieh and Pezeshk, 2011) showed that the $\mathrm{H} / \mathrm{V}$ method is very effective in determining the site fundamental frequency; however measurements and analysis should be performed with caution. The estimation of amplification of ground motion at resonance frequency using $\mathrm{H} / \mathrm{V}$ spectral ratios method is still controversial.

The depth to bedrock estimated in this work was interpreted using two published regression equations (Ibs-von Seht and Wohlenberg, 1999; Parolai et al., 2002). Depend on the obtained results, we used and illustrated only the estimated depth of sediments predicted from the regression equation of Ibs-von Seht and Wohlenberg (1999). This is because the bedrock depths predicted by the equation of Parolai et al (2002) are consistently deeper than those indicated by other available information about the study areas. On the other hand, the equation of Ibs-von Seht and Wohlenberg (1999) produces an interpreted bedrock surface most consistent with the geological setting of the investigated sites.

\section{CONCLUSION}

In the current work the ambient noise data which is fast, non invasive, and low cost tool was used in the estimation of shear wave velocity, fundamental site frequency and its corresponding amplitude, and 
Table 1 Results of H/V analysis at Hurghada and Safaga cities.

\begin{tabular}{cccclcc}
\hline Area & Site & $\begin{array}{c}\text { Latitude } \\
(\text { deg. })\end{array}$ & $\begin{array}{c}\text { Longitude } \\
(\text { deg. })\end{array}$ & $\begin{array}{c}f_{0}(\mathrm{~Hz}), \\
\text { sd }\end{array}$ & $\begin{array}{c}\text { H/V } \\
\text { Amplitude }\end{array}$ & $\begin{array}{c}\text { Depth to } \\
\text { bedrock } \\
(\mathrm{m})\end{array}$ \\
\hline \multirow{6}{*}{ Hurghada } & 1 & 27.3093 & 33.7202 & $0.93(+/-0.0917)$ & 4.9 & 105.8 \\
& 2 & 27.2469 & 33.8225 & $0.5(+/-0.0622)$ & 5.0 & 250.5 \\
& 3 & 27.2226 & 33.8391 & $0.45(+/-0.0666)$ & 3.6 & 289.9 \\
& 4 & 27.1816 & 33.8225 & $0.58(+/-0.683)$ & 4.1 & 203.8 \\
& 5 & 27.2941 & 33.7374 & $0.5(+/-0.081)$ & 6.8 & 250.5 \\
& 6 & 27.2514 & 33.8109 & $0.53(+/-0.0682)$ & 4.5 & 231 \\
& 7 & 27.2279 & 33.8349 & $0.66(+/-0.0955)$ & 2.4 & 170.3 \\
& 8 & 27.1958 & 33.8320 & $0.6(+/-0.0914)$ & 2.8 & 194.4 \\
& 9 & 27.2942 & 33.7532 & $0.88(+/-0.0388)$ & 4.3 & 114.3 \\
& 10 & 27.2632 & 33.8007 & $0.66(+/-0.0119)$ & 7.3 & 170.3 \\
& 11 & 27.2405 & 33.8274 & $0.43(+/-0.0136)$ & 4.6 & 308.8 \\
& 12 & 27.2078 & 33.842 & $0.51(+/-0.814)$ & 3.8 & 243.7 \\
& Ar_1 & 27.2743 & 33.7684 & $1.0(+/-0.0916)$ & 4.9 & 95.7 \\
\hline \multirow{5}{*}{ Safaga } & & & & & & \\
& 1 & 26.745 & 33.924 & $0.5(+/-0.0790)$ & 5.5 & 250.5 \\
& 2 & 26.756 & 33.938 & $0.4(+/-0.045)$ & 3.4 & 341.4 \\
& 3 & 26.754 & 33.934 & $0.44(+/-0.082)$ & 4.0 & 299 \\
& 4 & 26.758 & 33.93 & $0.5(+/-0.0253)$ & 3.7 & 250.5 \\
& 5 & 26.746 & 33.939 & $0.45(+/-0.0418)$ & 4.9 & 290 \\
& 6 & 26.761 & 33.944 & $0.35(+/-0.045)$ & 5.2 & 411 \\
& 7 & 26.779 & 33.933 & $0.5(+/-0.059)$ & 4.8 & 250.5 \\
& 8 & 26.756 & 33.945 & $0.35(+/-0.0623)$ & 8.5 & 411 \\
& Ar_2 & 26.739 & 33.939 & $0.53(+/-0.061)$ & 4.8 & 231 \\
\hline
\end{tabular}

bedrock depth which are the key components of seismic hazard studies at Hurghada and Safaga cities, Red Sea coast, Egypt. Two schemes were achieved; in the first scheme, we applied a joint inversion scheme of Rayleigh wave dispersion using a data set of seismic noise recordings collected by $2 \mathrm{D}$ arrays of seismic stations to infer the shear wave velocity structure at Hurghada and Safaga cities. We focused on the estimation of the Rayleigh wave dispersion curves using SPAC approach on the vertical component of ambient noise data. We focused on the joint inversion analysis of the observed dispersion curves. In particular, we performed the inversion of real data using the joint inversion scheme for Rayleigh wave dispersion. Moreover, comparing the Jacobian, model resolution, and data resolution matrices for the final best fit models obtained by scheme showed that when Rayleigh waves are considered, the shallower layers of the model can be better resolved.

In order to check the reliability of the obtained results, the frequency-wavenumber $(f-k)$ method was also applied as another supporting tool to drive the dispersion curve from the raw signals. This analysis focuses on the computation of Rayleigh wave phase velocities (dispersion curves) from the vertical component. The resulted dispersion curves were inverted using the neighborhood algorithm
(Sambridge, 1999 and Wathelet, 2008) to obtain the 1 -D shear-wave velocity profiles for the two arrays.

Comparison between the Vs models deduced from the two techniques shows a good agreement. Finally, comparing the shear wave velocity models estimated by the two approaches with a priori information of surface/subsurface geology about the study areas confirmed that the joint inversion of Rayleigh wave dispersion curves and $\mathrm{H} / \mathrm{V}$ spectral ratio curves can help to better constrain the shear wave velocity structure at the investigated sites.

In the second scheme, we applied the Horizontalto-Vertical (H/V) spectral ratio method (Nakamura, $1989)$ to estimate the fundamental site frequency $\left(f_{0}\right)$ and the corresponding amplitude of ground motion $\left(\mathrm{A}_{0}\right)$. The $\mathrm{H} / \mathrm{V}$ method uses a single, broad-band three-component seismometer to record ambient noise. The ratio of the averaged horizontal-to-vertical frequency spectrum is used to determine the fundamental site frequency, which interpreted using regression equations to estimate thickness of sediments/ depth to bedrock. The ambient noise data from the investigated sites, produced clear, easily identified resonance frequency peaks that correlate well with obtained depth to bedrock at Hurghada and Safaga cities. 

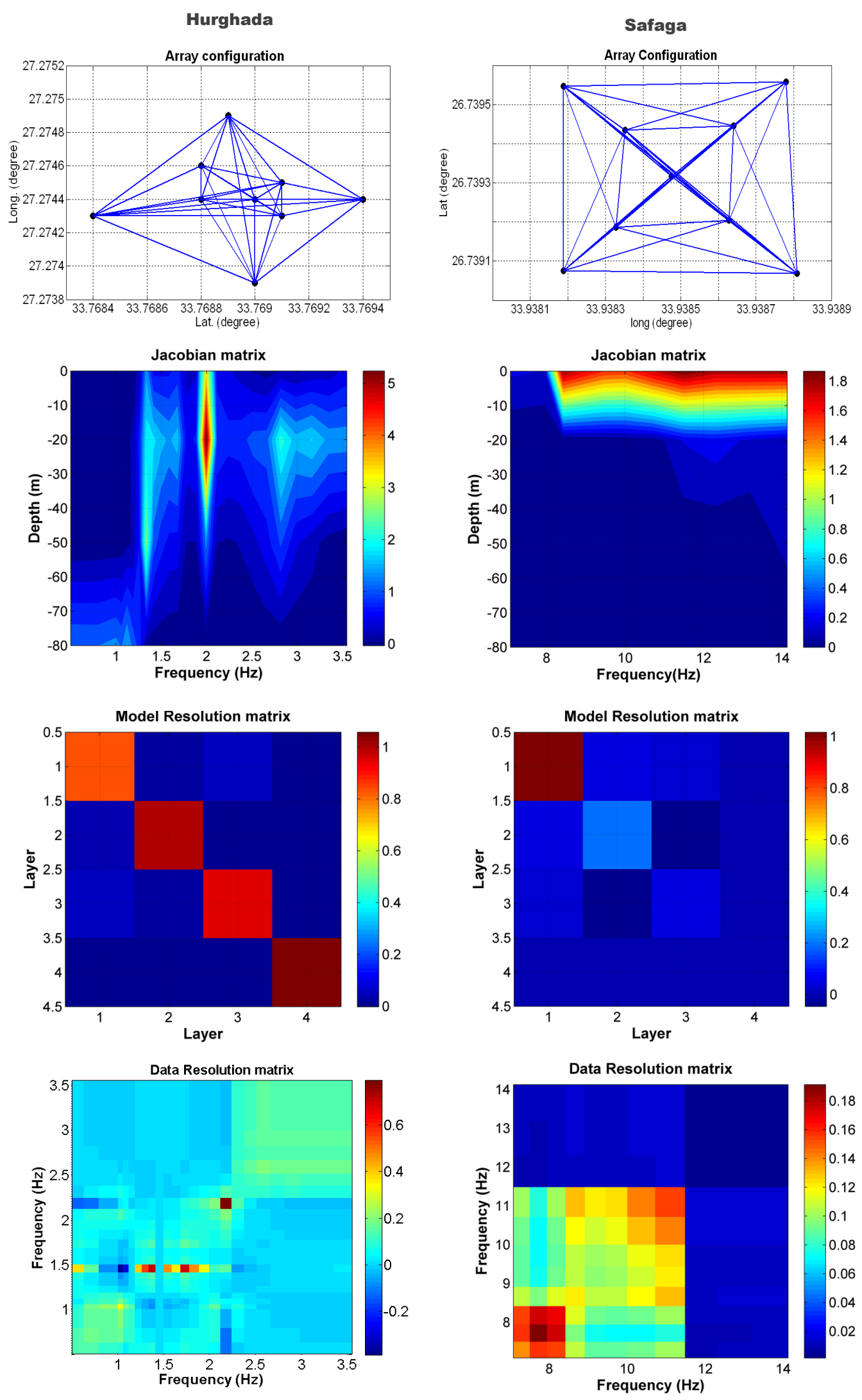

Fig. 3 Array configurations and matrices of Jacobian, model resolution and data resolution of Rayleigh waves for Hurghada and Safaga sites. 

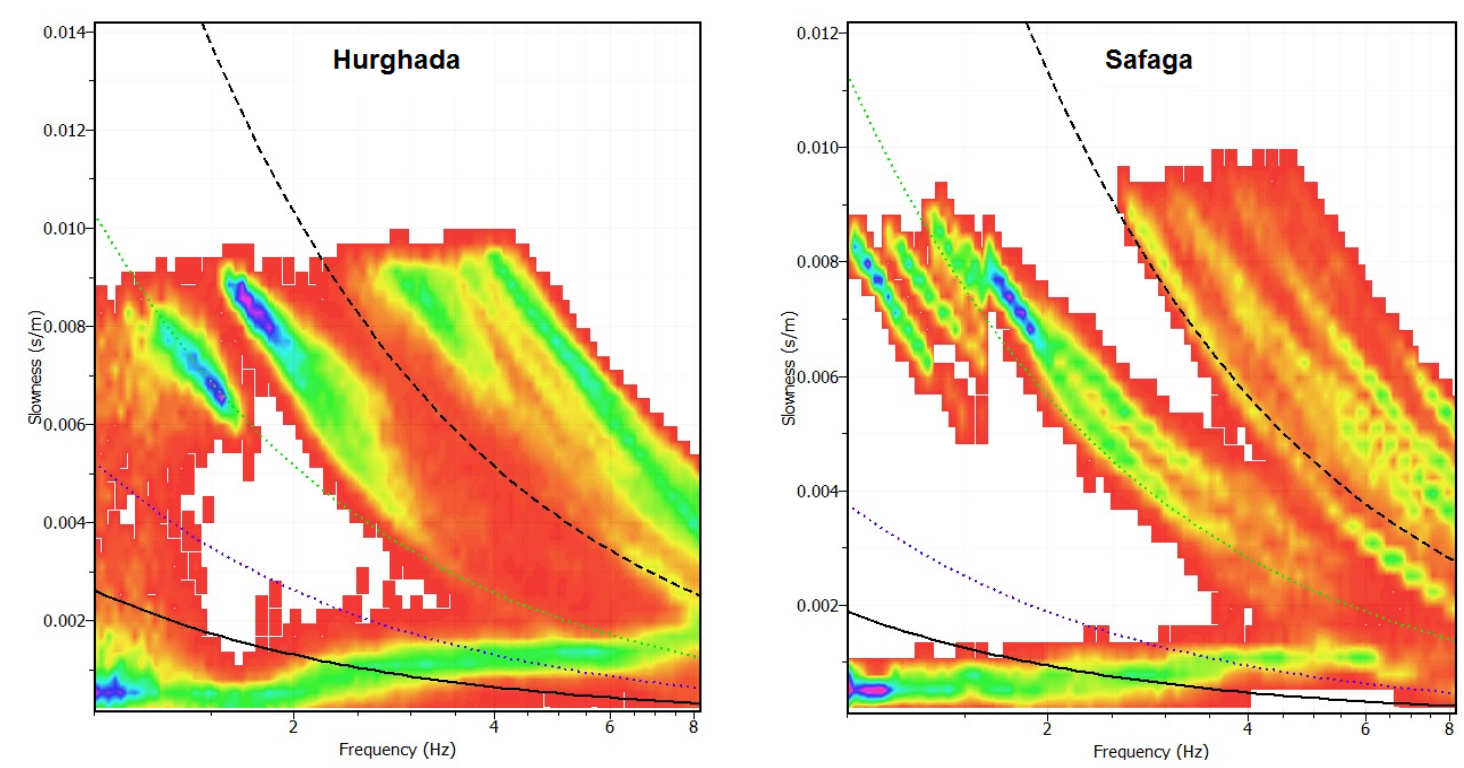

Fig. 4 Dispersion curves derived from $f-k$ analysis; left (Hurghada array), right (Safaga array). The four exponential curves represent constant wavenumber values: $k_{\min } / 2$ (continuous line), $k_{\min }$ (dotted blue line), $k_{\max } / 2$ (dotted green line) and $k_{\max }$ (dashed line).
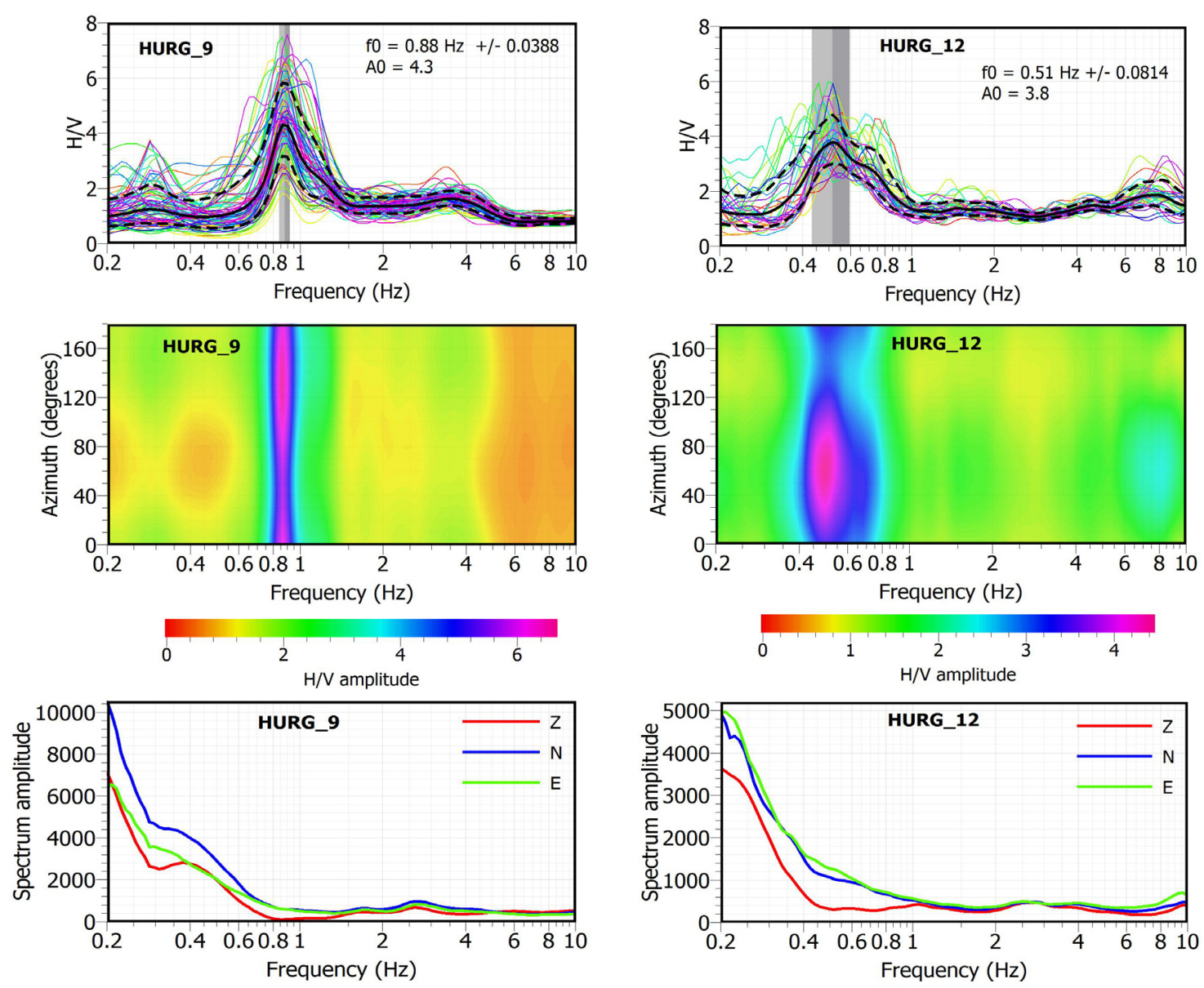

Fig. 5 Examples of the H/V results at Hurghada city. Upper: H/V spectral ratio curve; middle: H/V rotate plot; lower: spectrum of the three components. 

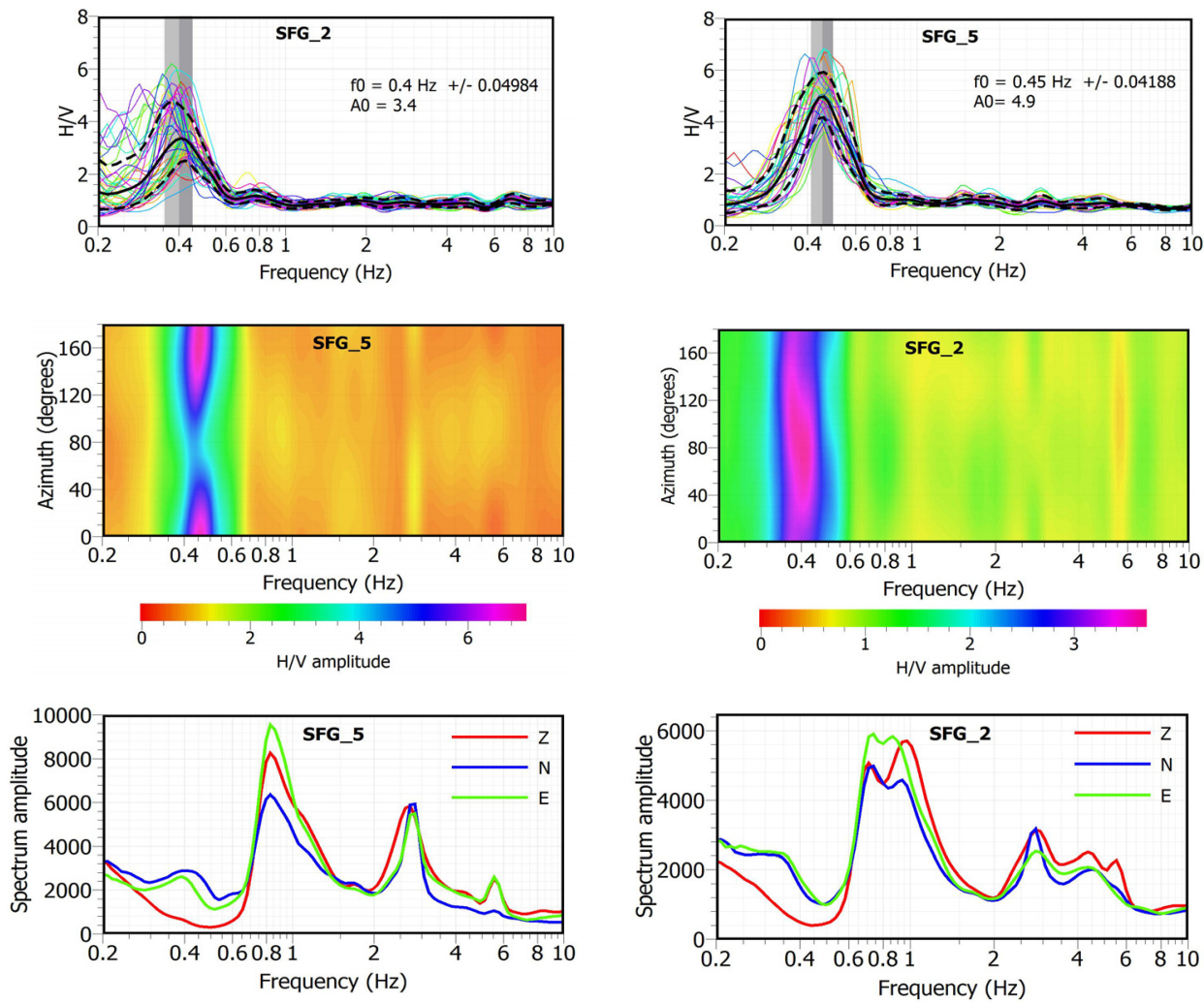

Fig. 6 Examples of the $H / V$ results at Safaga city. Upper: $H / V$ spectral ratio curve; middle: $H / V$ rotate; lower plot: spectrum of the three components.
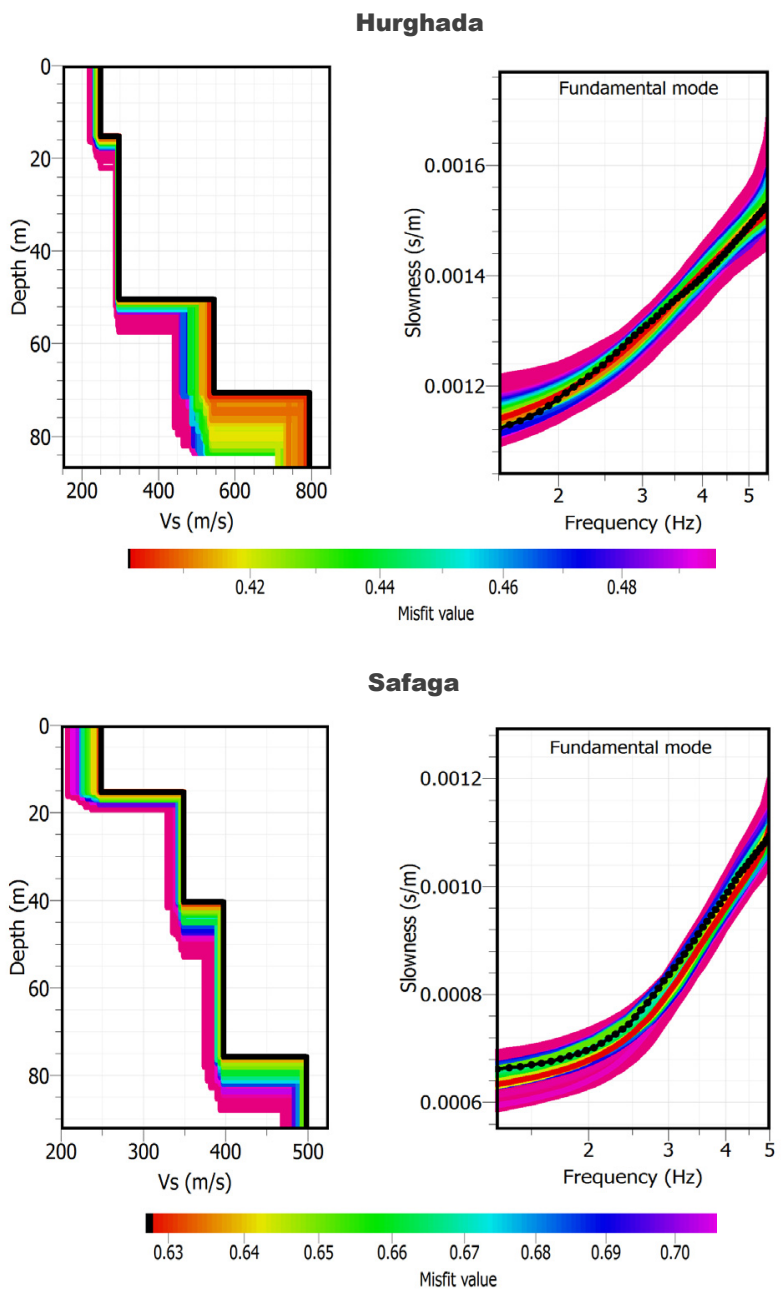

Fig. 8 The left panels illustrate S-wave velocity profiles resulted from $f-k$ analysis at Hurghada and Safaga cities, black line represents the model of lowest misfit. Right panels show Rayleigh wave dispersion curves, inverted (colors) and measured (black). 


\section{ACKNOWLEDGMENTS}

This study has been carried out and supported by the Department of Seismology, National Research Institute of Astronomy and Geophysics (NRIAG), Cairo, Egypt. We are immensely grateful to the anonymous reviewers for their valuable comments which are greatly helped to improve this paper.

\section{REFERENCES}

Abd el-aal, A.K.: 2008, Simulating time-histories and pseudo-spectral accelerations from the 1992 Cairo Earthquake at the proposed El-Fayoum New City Site, Egypt. Acta Geophys., 56, 1025-1042. DOI: $10.2478 / \mathrm{s} 11600-008-0054-6$

Abd el-aal, A.K.: 2010a, Eliminating upper harmonic noise in vibroseis data via numerical simulation. Geophys. J. Int., 181, 1499-1509.

DOI: $10.1111 / \mathrm{j} .1365-246 X .2010 .04594 . x$

Abd el-aal, A.K.: 2010b, Modeling of seismic hazard at the northeastern part of greater Cairo metropolitan area, Egypt. J. Geophys. Eng., 7, 75-90. DOI:10.1088/1742-2132/7/1/007

Abd el-aal, A. K.: 2010c, Ground motion prediction from nearest seismogenic zones in and around Greater Cairo Area, Egypt. Nat Hazards Earth Syst Sci, 10, 1495-1511. DOI: 10.5194/nhess-10-1495-2010

Abd el-aal, A. K.: 2013, Very broadband seismic background noise analysis of permanent good vaulted seismic stations. Journal of Seismology, 17, No. 2, 223-237. DOI: 10.1007/s10950-012-9308-5

Abd el-aal, A.K. and Soliman, M.S.: 2013, New seismic noise models obtained using very broadband stations. Pure Appl. Geophys., 170, No. 11, 1849-1857. DOI: $10.1007 / \mathrm{s} 00024-013-0640-7$

Abd el-aal, A. K., Kamal, H., Abdelhay, M. and Elzahaby, K.: 2015, Probabilistic and stochastic seismic hazard assessment for wind turbine tower sites in Zafarana Wind Farm, Gulf of Suez, Egypt. Bulletin of Engineering Geology and the Environment, 74, No. 4. DOI: $10.1007 / \mathrm{s} 10064-015-0717-x$

Abdel-Rahman, K., Abd el-Aal, A. K., El-Hady, S., Mohamed, A.A. and Abdel-Moniem, E.: 2012, Fundamental site frequency estimation at New Domiat city, Egypt. Arab. J. Geosci., 5, 653-661. DOI: $10.1007 / \mathrm{s} 12517-010-0222-2$

Abu El-Nader, I.: 2013, Source parameters and moment magnitude of 30 January 2012 earthquake, Northern Red Sea. Seis. Res. Letters, 84, No. 5, 805-809. DOI: $10.1785 / 0220120162$

Aki, K.: 1957, Space and time spectra of stationary stochastic waves, with special reference to microtremors. Bulletin of the Earthquake Research Institute, 35, 415-456.

Aki, K.: 1965, A note on the use of microseisms in determining the shallow structures of the Earth's crust. Geophysics, 29, 665-666.

Bard, P.Y.: 1998, Microtremor measurements: A tool for site effect estimation. Second International Symposium on the Effects of Surface Geology on Seismic Motion, Irikura, Kudo Okada \& Sasatani (eds), Balkema, 1251-1279.

Bard, P.Y.: 1999, Microtremor measurements: a tool for site effect estimation? In: Irikura, K, Kudo, K, Okada, H. and Sasatani, T. (eds) State-of-the-art paper, second international symposium on the effects of surface geology on seismic motion, Yokohama, December 13, 1998, 3. Balkema, Rotterdam, 1251-1279.
Bensen, G.D., Ritzwoller, M.H. and Shapiro, N.M.: 2008, Broadband ambient noise surface wave tomography across the United States. J. Geophys. Res., 113, B05 306. DOI: 10.1029/2007/JB005248

Brenguier, F., Shapiro, N.M., Campillo, M., Nercessian, A. and Ferrazzini, V.: 2007, 3D surface wave tomography of the Piton de la Fournaise Volcano using seismic noise correlations. J. Geophys. Res., 34, L02305. DOI: $10.1029 / 2006$ GL028586

Capon, J.: 1969, High-resolution frequency-wavenumber spectrum analysis. Proc. IEEE 57, 1408-1418.

Chavez-Garcia, F.J. and Luzon, F.: 2005, On the correlation of seismic microtremors. J. Geophys. Res., 110, B11 313. DOI: $10.1029 / 2005 J B 003671$

Conoco: 1987, Geological map of Egypt, Scale 1:500,000, NH36 SW-BENI SUEF sheet.

Curtis, A., Gerstoft, P., Sato, H., Snieder, R. and Wapenaar, K.: 2006, Seismic interferometry turning noise into signal. Leading Edge, 25, 1082-1092.

Delgado, J., López Casado, C., Giner, J., Estévez, A., Cuenca A. and Molina, S.: 2000, Microtremors as a geophysical exploration tool: Applications and limitations. Pure and Applied Geophysics, 157, No. 9, 1445-1462. DOI: 10.1007-PL00001128

Duval, A.M., Bard, P.Y., Meneroud, J.P. and Vidal, S.: 1994, Usefulness of microtremor measurements for site effect studies. In: Duma, G. (ed), Proceedings of the tenth European conference on earthquake engineering, Vienna, Austria, I. Balkema, Rotterdam, 521-528.

EGPC: 1987, Geological Map of Egypt 1:500000, The Egyptian General Petroleum Corporation (EGPC), Cairo, Egypt.

El-Eraki, M., Mohamed, A.A., El-Kenawy, A.A., Toni, M.S. and Imam, S.M.: 2012, Engineering seismological studies in and around Zagazig city, Sharkia, Egypt. NRIAG Journal of Astronomy and Geophysics, 12, 1(2), 141-151. DOI: $10.1016 /$ j.nrjag.2012.12.009

El-Hady S., Fergany, S., Othman, A. and Mohamed, G.K.: 2012, Seismic microzonation of Marsa Alam, Egypt using inversion HVSR of microtremor observations. J Seismol, 16, No. 1, 55-66. DOI: $10.1007 / \mathrm{s} 10950-011-9249-4$

Ibs-von Seht, M., and Wohlenberg, J.: 1999, Microtremors measurements used to map thickness of soft sediments. Bulletin of the Seismological Society of America, 89, No. 1, 250-259.

Kanai, K. and Tanaka, T.: 1961, On microtremors VIII. Bull Earthq Res Inst, Tokyo University, 39, 97-114.

Hagshenas, E., Bard, P.-Y., Theodulidis, N., and SESAME WP04 Team: 2008, Empirical evaluation of microtremor $\mathrm{H} / \mathrm{V}$ spectral ratio, Bull. Earthquake Engineering 6, 75-108. DOI: $10.1007 / \mathrm{s} 10518-007-9058-\mathrm{x}$

Kang, T.S. and Shin, S.J.: 2006, Surface wave tomography from ambient seismic noise of accelerograph networks in Southern Korea. Geophys. Res. Lett., 33, L17 303. DOI: 10.1029/2006GL027044

Konno, K. and Ohmachi, T.: 1998, Ground motion characteristics estimated from spectral ratio between horizontal and vertical components of microtremor. Bulletin of the Seismological Society of America, 88, No. 1, 228-241.

Lachet, C., Hatzfeld, D., Bard, P.Y., Theodulidis, N., Papaionnou, C. and Savvaidis, A.: 1996, Site effects and microzonation in the city of Thessaloniki 
(Greece). Comparison different approaches. Bull Seismol Soc Am, 86, No. 6, 1692-1703.

Lin, F., Ritzwoller, H.M., Townend, J., Savage, M. and Bannister, S.: 2007, Ambient noise Rayleigh wave tomography of New Zealand. Geophys. J. Int., 170, No. 2, 649-666. DOI: $10.1111 /$ j.1365-246X.2007.03414.x

Malagnini, L., Rovelli, A., Hough, S. and Seeber, L.: 1993, Site amplification estimates in the Garigliano valley, central Italy, based on dense array measurements of ambient noise. Bulletin of the Seismological Society of America, 83, No. 6, 1744-1755.

Moschetti, M.P., Ritzwoller, H.M. and Shapiro, M.N.: 2007, Surface wave tomography of the western United States from ambient seismic noise: Rayleigh wave group velocity maps. Geochem. Geophys. Geosyst., 8, Q08 010. DOI:10.1029/2007GC001655

Mukhopadhyay, S. and Bormann, P.: 2004, Low cost seismic microzonation using microtremor data: an example from Delhi, India. Journal of Asian Earth Science, 24, 271-280.

DOI: $10.1016 /$ j.jseaes.2003.11.005

Nakamura, Y.: 1989, A method for dynamic characteristics estimations of subsurface using microtremors on the ground surface. Quarterly Report, RTRI, Japan, 30, 25-33.

Nogoshi, M. and Igarashi, T.: 1971, On the amplitude characteristics of microtremors. J Seismol Soc Jpn, 24, 24-40.

Ohori, M., Nobata, A. and Wakamatsu, K.: 2002, A comparison of esac and fk methods of estimating phase velocity using arbitrary shaped microtremor arrays. Bulletin of Seismologial Society of America, 92, No. 6, 2323-2332. DOI: 10.1785/0119980109

Okada, H.: 2003, The Microtremor Survey Method. Geophysial Monograph, Series 12.

Panou, A.A., Theodulidis, N., Hatzidimitriou, P., Stylianidis, K., Papazachos, C.B.: 2005, Ambient noise horizontal-to-vertical spectral ratio in site effects estimation and correlation with seismic damage distribution in urban environment: the case of the city of Thessaloniki (Northern Greece). Soil Dynamics and Earthquake Engineering, 25, 261-274. DOI: $10.1016 /$ j.soildyn.2005.02.004

Parolai, S., Bormann, P. and Milkert, C.: 2002, New relationships between Vs, thickness of sediments and resonance frequency calculated by the $\mathrm{H} / \mathrm{V}$ ratio of seismic noise for Cologne area (Germany). Bulletin of Seismologial Society of America, 92, No. 6, 25212527. DOI: $10.1785 / 0120010248$

Parolai, S., Bindi, D., Boumbach, M., Grosser, H., Milkereit, C., Karakisa, S. and Zuenbuel, S.: 2004, Comparison of different site response estimation techniques using aftershocks of the 1999 Izmit earthquake. Bulletin of Seismologial Society of America, 94, No. 3, 1096-1108.

DOI: $10.1785 / 0120030086$

Picozzi, M., Parolai, S., Bindi, D. and Strollo, A.: 2009, Characterization of shallow geology by highfrequency seismic noise tomography. Geophys. J. Int., 176, No. 1, 164-174.

DOI: 10.1111/j.1365-246X.2008.03966.x

Rial, J.A., Saltzman, N.G. and Ling, H.: 1992, Earthquakeinduced resonance in sedimentary basins. American Scientist, 80, No. 6, 566-578.
Said, R.: 1990, The geology of Egypt. Rotterdam Pup.Co, $722 \mathrm{pp}$.

Sambridge, M.: 1999, Geophysical inversion with a neighbourhood algorithm: I. Searching a parameter space. Geophys. J. Int., 138, No. 2, 479-494. DOI: 10.1046/j.1365-246X.1999.00876.x

Satoh, T., Kawase, H. and Matsushima, S.I.: 2001b, Estimation of S-wave velocity structures in and around the Sendai Basin, Japan, using array records of microtremors. Bull. Seism. Soc. Am., 91, No. 2, 206218. DOI: $10.1785 / 0119990148$

Schuster, G.: 2009, Seismic Interferometry, Cambridge University Press, Cambridge.

SESAME: 2004, Site Effects Assessment Using Ambient Excitations: Guidelines for the implementation of the $\mathrm{H} / \mathrm{V}$ spectral ratio technique on ambient vibrations measurements, processing and interpretation. European research project, WP12 - Deliverable D23.12, December 2004.

Shapiro, N.M., Campillo, M., Stehly, L. and Ritzwoller, M.: 2005, High resolution surface wave tomography from ambient seismic noise. Science, 307, No. 5715, 16151618. DOI: $10.1126 /$ science. 1108339

Snieder, R., Miyazawa, M., Slob, E. and Vasconcelos, I.: 2009, A comparison of strategies for seismic interferometry. Surv. Geophys., 30, 503- 523. DOI: 10.1007/s10712-009-9069-z

Toni, M.: 2007, Geotechnical and site effect studies in Hurghada city, Red Sea, Egypt. M.Sc. thesis, Faculty of Science, Assiut University, Egypt.

Toni, M.: 2012, Site response and seismic hazard assessment for the southern part of Cairo city, Egypt. $\mathrm{PhD}$ dissertation, Faculty of Science, Assiut University, Egypt.

Wapenaar, K., Draganov, D. and Robertsson, J.O.A.: 2008, Seismic interferometry: history and present status, in SEG Geophysics Reprints Series 26, Society of Exploration Geophysics, Tulsa, OK.

Wathelet, M.: 2005, Array recordings of ambient vibrations: surface-wave inversion. $\mathrm{PhD}$ thesis, Université de Liège, Belgium.

Wathelet, M.: 2008, An improved neighborhood algorithm: parameter conditions and dynamic scaling. Geophysical Research Letters, 35, L09301. DOI: 10.1029/2008 GL033256

Wathelet, M., Jongmans, D., Ohrnberger, M. and BonnefoyClaudet, S.: 2008, Array performances for ambient vibrations on a shallow structure and consequences over Vs inversion. J. Seismol., 12, 1-19. DOI: 10.1007/s10950-007-9067-x

Yang, Y., Ritzwoller, H.M., Levshin, L.A. and Shapiro, M.N.: 2007. Ambient noise Rayleigh wave tomography across Europe. Geophys. J. Int., 168, No. 1, 259-274. DOI: $10.1111 / j .1365-246 X .2006 .03203 x$

Yao, H., Van der Hilst, R.D. and de Hoop, M.V.: 2006, Surface wave tomography in SE Tibet from ambient seismic noise and two-station analysis. I. Phase velocity maps. Geophys. J. Int., 166, No. 2, 732-744. DOI: $10.1111 / \mathrm{j} .1365-246 X .2006 .03028 \mathrm{x}$

Zandieh, A. and Pezeshk, S.: 2011, A Study of horizontalto-vertical component spectral ratio in the New Madrid Seismic Zone. Bull. Seism. Soc. Am., 101, No. 1, 287-296. DOI: 10.1785/0120100120 